Dept. of Avian Diseases,

Animla Health Research Institute, Dokki

\title{
BACTERIOLOGICAL AND PATHOLOGICAL FINDINGS ON PASTEURELLOSIS IN OSTRICHES
}

(With 5 Tables and 16 Figures)

\author{
By \\ A.M. SHALABY and AMAL I. YOSEIF \\ (Received at 12/6/2008) \\ دراسة بكتريولوجية وباثولوجية على عدوى الباستيريلا فى النعام \\ محمود حمدى شلبح ، أمال ابراهيم بيوسف
}

فى محاولة لأكتشاف دور الباسيتريلا مالتوسيدا فى المشكلات المرضية فى مز ارع النعام فى في

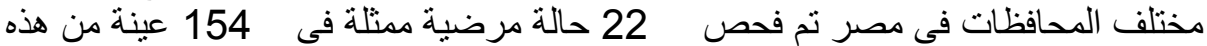

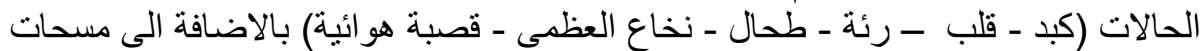

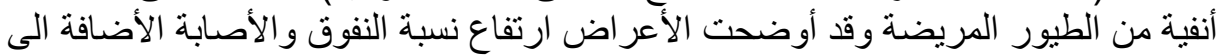

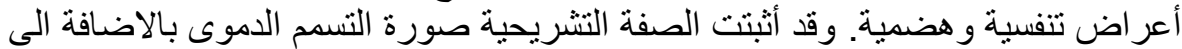

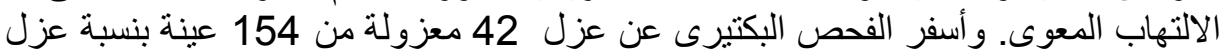

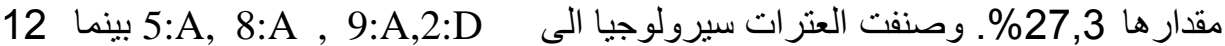

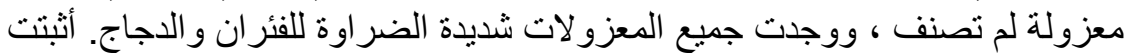

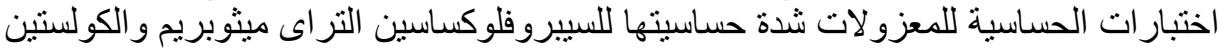

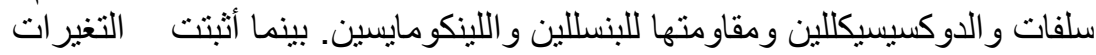

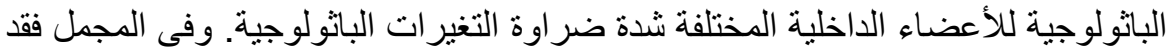

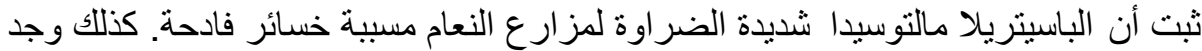

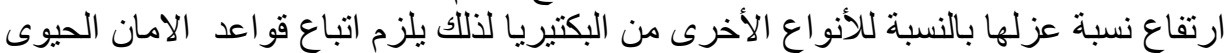

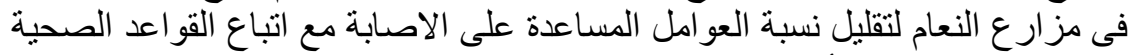

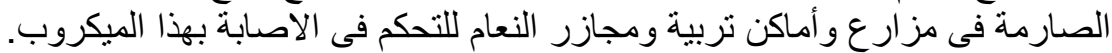

\section{SUMMARY}

In a trial to investigate the role of Pasteurella multocida in disease problems in ostrich farms at different provinces in Egypt. Twenty two cases are obtained and 154 samples from these cases (liver, heart, spleen, lung, trachea and Bone marrow) beside Nasal cleft swab from diseased birds. The clinical signs revealed high morbidity and mortality with respiratory distress and gastroenteric findings. The post mortem findings 
revealed a picture of hemorrhagic septicemia with enteritis. Bacteriological Examination revealed isolation of 42 isolates from 154 samples with a percentage of $27.3 \%$. The serotyping of the isolated strains revealed that they belong to serotypes 5: A, 8: A, 9: A and 2: D while 12 isolated strains were untyped. All the isolated strains were highly pathogenic for mice and chickens. The antibiogram test revealed that highly sensitive to ciprofloxacin, trimethoprim, colistin sulphate and doxycycline and resistant for penicillin, lincomycin. The pathological changes in different internal organs revealed highly pathological changes. It could be concluded that Pasteurella multocida is highly pathogenic for ostriches and cause severe losses in ostrich farms and found that the rate of isolation of Pasterulla multocida is very high in most bacterial agents. Therefore biosecurity measures must be completely used to minimize the predisposing factors with strict hygienic measures at the farm slaughter house and back yard of ostrich farms.

Key words: Ostrich, pasteurellosis, P. multocida

\section{INTRODUCTION}

Pasteurellosis in commercial poultry is usually associated with Pasteurella maltocida. There is many documented cases of Pasteurellosis in ostriches (Hala and Kawther, 2006; Moursi and Husein, 2007; Fatma and Hala, 2008).

Pasteurelosis occurs extensively in backyard and ornamental poultry. Ostriches have become commercially farmed animals in several countries of the world. Since 1999, there has been a dramatic increase in the number of ostriches. Although some technical information is available on the necessary conditions required for the successful rearing of ostrich chicks under farming conditions (Deeming and Ayres, 1994) problems still exist that are characterized by variations in growth rate which can adversely affect the value of the bird for breeding or slaughter. Infectious and nutritional diseases are some of the constraints to available ostrich. Ostriches are susceptible to numerous diseases of bacterial, fungal or parasitic origin. For some diseases affecting ostriches, new methods of control are poorly documented and an attempt was made to apply methods used in poultry biosecurity to ostriches (Huchzer meryer, 1996 and Cooper 2005). There are no effective 
vaccination protocols for ostriches and ideal standards of hygiene and quarantine are needed to prevent introduction of infection into ostrich flocks (Tully and Shane, 1996).

The aims of the present study were:

1 - Isolation and identification of P.multocida from ostriches with studying its pathogenicity and antibiotic sensitivity to various antibiotics.

2- Studying the histopathological changes associated with Pasteurellosis in ostriches.

\section{MATERIALS and METHODS}

\section{Collected samples:}

A total of 10 ostriches farms were examined from different governorates in Egypt (Alexandria, Sharkia, Ismaelia and kalubia) for the presence of Pasteurella infection (Table 1). Samples were collected from organs of ostrich both freshly dead and slaughtered.

\section{Histopathological examination:}

Specimens of trachea, lung, liver, proventriculus, pancreas, kidney and spleen were taken from the diseased ostriches and fixed in $10 \%$ neutral buffered formalin. The fixed specimens were trimmed, washed dehydrated in different concentrations of alcohols, cleared in xylol and embedded in paraffin. The paraffin embedding blocks were cut into sections sum and stained with Haematoxylin and Eosin (H\&E) according to Bancraft et al. (1990).

\section{Bacteriological examination:}

The collected samples included, heart, liver, spleen, bone marrow and nasal cleft swabs were submitted to Poultry Diseases Department, Animal Health Research Institute, Dokki, Giza, in which the case history, clinical signs and postmortem examination were recorded.

All the collected samples were examined bacteriologically according to (Snipes et al., 1990) as follow: the collected samples were inoculated in brain heart infusion broth (Oxoid) incubated at $37^{\circ} \mathrm{C}$ for 24 hrs. Direct cultivation of different samples on blood agar, Nutrient agar and MacConkey agar plates and incubated at $37^{\circ} \mathrm{C}$ for $24 \mathrm{hrs}$. A loopful of each broth culture were inoculated on blood agar, MacConkey agar plates (Oxoid) and incubated at $37^{\circ} \mathrm{C}$ for $24 \mathrm{hrs}$. Isolated colonies were picked up and identified morphologically, microscopically and biochemically according to (Holt et al., 1996). 
Pathgenicity testing of each of the suspected isolates was carried out by inoculation of two mice $\mathrm{I} / \mathrm{P}$ with $0.2 \mathrm{ml}$ of over night broth culture of the suspected P. multocida isolates. Blood smears from dead mice were stained with Giemsa stain for detection of Pasteurella bipolarity and inoculated on blood agar plates for re-isolation of the microorganism.

Serological identification:

Capsular typing of involved strains were determined by indirect haemagglutination test according to Carter and Rappay (1962) using diagnostic type specific Pasteurella maltocida antisera (type A, B, D and E).

\section{Antibiotic susceptibility tests:}

In-vitro susceptibility testing of $P$. multocida isolates to various antimicrobial agents was determined against twelve different commercial antibiotic discs (Oxoid) according to Quinn et al. (1994).

\section{Pathogenicity tests of $P$. maltocida isolates:}

\section{1- In mice:}

A total of fifty Swiss mice were used for pathogenicity testing of the isolated serovars which were proved to be free from pasteurella infection. The mice were divided into five equal groups (10 mice per group). Mice in groups number 1, 2, 3 and 4 were infected intraperitoneally (I/P) with $0.2 \mathrm{ml}$ of overnight broth culture of one of the isolated pasteurella serovars (5: A, 8: A, 9: A and 2: D respectively) while mice in group (5) were kept as control non-infected group. Mice in each group were monitored for clinical signs and mortality for 7 days and deaths were recorded.

\section{2- In chickens:}

A total of fifty, 8 weeks old white leghorn chickens and suitable balanced ration were brought from commercial farm. Chickens were proved to be free from Pasteurella infection. Chickens were divided into 5 equal groups (10 chickens per group). Chickens in groups number 1, 2, 3 and 4 were infected intra- nasal with $0.2 \mathrm{ml}$ of overnight broth culture of one of the isolated Pasteurella serovars (5:A, 8:A, 9:A and 2:D respectively) while chickens in group (5) were kept as control noninfected group. Chickens in each group were monitored for clinical signs and mortality for 7 days and deaths were recorded.

\section{RESULTS}




\section{1- Clinical signs:}

Among the affected birds were varied according to the severity of the disease, but generally these were gastrointestinal troubles manifested by diarrhea with offensive odor- other signs as emaciation, dullness, inappetence and recumbency before death were recorded. Respiratory distress and dyspnea were also common with nasal discharge as well as conjunctivitis.

\section{2- Postmortem findings:}

It revealed a picture of septicemia congestion of the liver, lung and spleen with enlargement of the heart and thick pericardium were seen severe congestion of the intestine. Bacterial isolation and Identification revealed that Pasteurella multocida isolated from different provinces (Alexandria, Sharkia, Ismaelia and Kaluobia) with the percentage of $(28.6 \%, 31.4 \%, 28.6 \%$ and $52.4 \%)$ respectively according to the number of samples from each of them. Table (1) the percentage of the isolated Pasteurella multocida from different samples of ostrich birds were reported in Table (1).

- The serotyping of the isolates revealed that 5: A, 8: A, 9: A, 2: D and untype isolates were reported in Table (2).

- The pathogenicity tests of the isolated strains were more pathogenic for mice and chicken. The results are shown in Table (4) and (5).

- The results of antibiogram sensitivity test are mentioned in Table (3).

- In the present study a wide spread pathological changes in different organs are recorded.

\section{In the present study:}

Therefore a wide spread pathological changes in different organs were recorded. It could be concluded that the most bacterial pathogens which detected in ostrich farms were Pasteurella multocida so; successful management and disinfection of farms must be carried with therapy to eliminate the predisposing factor as much as possible.

\section{Pathological lesions of internal organs of freshly dead ostriches:}

Trachea, the surface epithelium of lamina propria showed hyperplasia (Fig. 1). Thickening of the mucosa due to edema,congested blood vessels, haemorrhage and inflammatory cells infelteration (Fig. 2).

Lung lesions consisted of haemorrhage. (Fig. 3), diffuse infelteration and focal aggregation of mononuclear cells mainly lymphocyte, fibrinous component is most prominent (Fig. 4). 
Liver, the hepatic vessels of most cases showed congestion with subcapsuler haemorrhage. Some of the hepatic cells suffered from vaculer and granular degeneration in addition to activation of kuffer cells Fig. 5). Haemorrhage was seen (Fig. 6). Somstimes the portal area exhibited inflammatory cells aggregation, some cases revealed coagulativ necrosis.

Kidney lesions consisted of moderate congestion of blood vessels and haemorrhage (Fig. 7), The renal tubules suffered from necrobiotic changes, epithelial denudation and granular degeneration (Fig. 8), lymphocytic aggregation between the tubules was exist. Necrosis of renal tubules which replaced by inflammatory cells (Fig. 9) and edema in ureter (Fig. 10).

Spleen, microscopical changes revealed severe haemorrhage, haemosedrosis (Fig. 11) and multipl focal necrosis of apleomorphic cells (Fig. 12).

Heart lesions consisted of pericarditis, congestion of blood vessels haemorrahages and dispertion of myelocytes due to edema and inflammatory cells infiltration (Fig. 13) and myomalacia.

Proventriculus, showed hyperplasia of epithelial lining, congestion and inflammatory cells infiltration in mucosal layer. There was degeneration of glandular epithelium, haemorrhage and lymphocytic infiltration (Fig. 14).

Pancrease, showed necrobiotic changes (Fig. 15) and haemorrhage (Fig. 16). 
Table 2: Incidence of isolation of $P$. multocida serovars from ostriches cases in different Governorates.

\begin{tabular}{|c|c|c|c|c|c|c|}
\hline Governorate & $\begin{array}{c}\text { No. of isolated } \\
\text { serovars }\end{array}$ & $5: \mathrm{A}$ & $8: \mathrm{A}$ & $9: \mathrm{A}$ & $2: \mathrm{D}$ & Untype \\
\hline
\end{tabular}


Assiut Vet. Med. J. Vol. 54 No. 118 July 2008

\begin{tabular}{|c|c|c|c|c|c|c|}
\hline Alexandria & 15 & 3 & 6 & 2 & 1 & 3 \\
\hline Sharkia & 9 & 1 & 2 & 1 & 1 & 4 \\
\hline Ismailia & 11 & 2 & 3 & 2 & 1 & 3 \\
\hline Kalubia & 7 & 1 & 2 & 1 & 1 & 2 \\
\hline Total & 42 & 7 & 13 & 6 & 4 & 12 \\
\hline
\end{tabular}

Table 3: Antibiotic susceptibility tests of the $42 P$. maltocida isolates from ostriches:

\begin{tabular}{|c|c|c|c|c|c|c|}
\hline Type of antibiotic disc & \multirow{2}{*}{$\begin{array}{c}\text { Disk } \\
\text { Concentration }\end{array}$} & \multirow{2}{*}{$\begin{array}{c}\text { Standard zone of } \\
\text { inhibition }\end{array}$} & \multicolumn{4}{|c|}{ Antibiotic sensitivity } \\
\cline { 4 - 7 } & $(\mu \mathrm{g})$ & $(\geq)$ & \multicolumn{3}{|c|}{$\mathrm{S}$} & \multicolumn{3}{|c|}{$\mathrm{R}$} \\
\cline { 4 - 7 } & 25 & 13 & 27 & 64.3 & 15 & 35.7 \\
\hline Amoxicillin & 20 & 16 & 12 & 28.6 & 30 & 71.4 \\
\hline Ampicillin & 25 & 8 & 31 & 73.8 & 11 & 26.2 \\
\hline Colistin sulphate & 1.25 & 24 & 38 & 90.5 & 4 & 9.5 \\
\hline Trimethoprim & 5 & & 40 & 95.2 & 2 & 4.8 \\
\hline Ciprofloxacin & 30 & 14 & 24 & 57.1 & 18 & 42.9 \\
\hline Oxytetracycline & 10 & 16 & 0 & 00.0 & 42 & 100 \\
\hline Penicillin & 2 & 15 & 12 & 28.6 & 30 & 71.4 \\
\hline Lincomycin & 30 & 22 & 22 & 52.4 & 20 & 47.6 \\
\hline Flumequine & 30 & 14 & 30 & 71.4 & 12 & 28.6 \\
\hline Doxycyline & 30 & 31 & 25 & 59.5 & 17 & 40.5 \\
\hline Chloramphenicol & 10 & 22 & 35 & 83.3 & 7 & 16.7 \\
\hline Enrofloxacin & & & & & & \\
\hline
\end{tabular}

Table 4: Pathogenicity of P. multocida isolated from ostriches in mice

\begin{tabular}{|c|c|c|c|c|c|}
\hline Group No. & Infected serotype & \multirow{2}{*}{ No. of mice } & \multirow{2}{*}{ Route } & \multicolumn{2}{|c|}{ Mortality } \\
\cline { 4 - 6 } & & & & No. & $\%$ \\
\hline 1 & 5:A & 10 & I/P & $7 / 10$ & 70 \\
\hline 2 & 8:A & 10 & I/P & $8 / 10$ & 80 \\
\hline 3 & $9: \mathrm{A}$ & 10 & I/P & $6 / 10$ & 60 \\
\hline 4 & 2:D & 10 & I/P & $5 / 10$ & 50 \\
\hline 5 & Control non-infected & 10 & I/P & 0 & 0 \\
\hline
\end{tabular}

Table 5: Pathogenicity of $P$. multocida isolated from ostriches in chickens:

\begin{tabular}{|c|c|c|c|c|c|}
\hline Group No. & Infected serotype & \multirow{2}{*}{ No. of mice } & \multirow{2}{*}{ Route } & \multicolumn{2}{|c|}{ Mortality } \\
\cline { 5 - 6 } & & & & No. & $\%$ \\
\hline 1 & 5:A & 10 & $\mathrm{I} / \mathrm{P}$ & $9 / 10$ & 90 \\
\hline 2 & $8: \mathrm{A}$ & 10 & $\mathrm{I} / \mathrm{P}$ & $8 / 10$ & 80 \\
\hline 3 & 9:A & 10 & $\mathrm{I} / \mathrm{P}$ & $6 / 10$ & 60 \\
\hline 4 & 2:D & 10 & $\mathrm{I} / \mathrm{P}$ & $6 / 10$ & 60 \\
\hline 5 & Control non-infected & 10 & $\mathrm{I} / \mathrm{P}$ & $0 / 10$ & 00 \\
\hline
\end{tabular}


Assiut Vet. Med. J. Vol. 54 No. 118 July 2008 
Assiut Vet. Med. J. Vol. 54 No. 118 July 2008

\section{HISTOPATHOLOGICAL FIGURES}


Fig. 1: Trachea of diseased ostrichs showing hyperplasia of epithelial lineing lamina propria.

(H-E x100)

Fig. 2: Trachea of diseased ostrichs showing edema and haemorrhage in mucosa.

(H-E x100)

Fig. 3: Lung of diseased ostrichs showing haemorrhage.

Fig. 4: Lung of diseased ostriches showing fibrinous exudates.

(H-E x250)

(H-E x100)

Fig. 5: Liver of diseased ostriches showing vacular degeneration.

(H-E x400)

Fig. 6: Liver of diseased ostriches showing hemorrhage and coagulative necrosis.

(H-E x 100)

Fig. 7: Kidney of diseased ostriches showing hemorrhage.

(H-E x250)

Fig. 8: Kidney of diseased ostriches showing denudation of renal tubule.

(H-E x250)

Fig. 9: Kidney of diseased ostriches showing necrosed tubules which replaced by inflammatory cell.

(H-E x 100)

Fig. 10: kidney of diseased ostriches showing edema in ureter.

(H-Ex100)

Fig. 11: Spleen of diseased ostriches showing severe haemorrhage.

(H-E x100)

Fig. 12: Spleen of diseased ostriches showing multiple focal necrosis of pleomorphic cells.

(H-E x400)

Fig. 13: Heart of diseased ostriches showing dispertion of myelocytes due to edema and inflammatory cells.

(H-E x 250)

Fig. 14: Proventriculus of diseased ostriches showing degeneration of glandular epithelium and hemorrhage with lymphocytic infiltration.

(H-E x100)

Fig. 15: Pancreas of diseased ostriches showing necrobiotic changes.

(H-E x 250)

Fig. 16: Pancreas of diseased ostriches showing hemorrhage. (H-Ex250)

\section{DISCUSSION}

The growing interest in commercial production of ostriches all over the world including Egypt has accompanied progress in researches concerning diagnosis and control of ostrich diseases. Young chicks are more susceptible to bacterial infection and parasitic diseases associated with relatively high mortality (Huchzermeyer, 1999, Tully, 2000 and Cooper, 2005). 
The clinical signs of affected ostriches were varied according to severity of the disease in affected birds but generally respiratory distresses and dyspnea were recorded with ocular and nasal discharge, conjunctivitis. The results agreed with Sohair and Moursi (2003) and Sahinduran (2004). Gastrointestinal troubles which were manifested by diarrhea with offensive odor. Poor growth, emaciation and recumbencey before death were observed. These clinical observation were similar to those reported by Tully and Shan (1998); El Demerdech et al. (2003); and Moursi and Husien (2007).

Post-mortem examination revealed a picture of septicemia, congestion of the liver, lung, and spleen with enlargement of the heart. Similar post mortem picture was recorded by Okoh (1980), Tully and Shan (1998), El- Demerdach et al (2003) and Moursi and Husien (2007).

Bacteriological examination revealed that Pasteurella multocida were isolated with percentage of $27.3 \%$ in our study but Nasef et al. (2003) who reported the Pasteurella multocida with a percentage of $6.61 \%$.

The incidence of bacterial isolate from diseased and dead birds was very high in Pasteurella multocida. This result confirms that obtained by El-Faki et al. (2002) and Sohair and Moursi (2003) who reported the isolation Pasteurella multocida from septicemic cases in ostrich. These findings also supported by Rabab (2003) and Moursi and Husien (2007) serological serotypes of Pasteurella multocida was found to be belonged to (5: A, 8: A, 9: A, 2: D and 12 untyped) (16.7\%, $30.95 \%, 14.3 \%, 9.5 \%$ and 28.6$)$ respectively. These serotypes are similar to those reported by Nasef et al (2003) and Fatma and Hala (2008) the sensitivity test of Pasteurella multocida serotypes revealed that ciprofloxacin, trimethoprim, Enrof loxaein, colistin suplate, Doxycyline, Amoxicillin chloramphenicol and oxyteteracycline. These results agreed with Zahraei and Farashi (2006) and Moursi and Husien (2007) and Fatma and Hala (2008). Such variation in sensitivity might be due to repeated use of special type of antibiotic therapy Jaslow et al. (1981), presence of resistant mutants strains, difference in geographics areas and time of isolation, may reflect differences in pattern of drug use, are due to recent isolates were more resident to antimicrobial against the old isolates of Pasteurella multocida (Chang, 1982).

Pasteurella multocida isolates was highly pathogenic for mice and chickens. The mortality in mice $(70 \%, 80 \%, 60 \%$ and $50 \%)$ when infected by 5: A, 8: A, 9: A and 2: D) respectively but in chickens (90\%, 
$80 \%, 60 \%$ and 60\%) when infected by 5: A, 8: A, 9: A and 2: D respectively. In our study this agreed with Nasef, et al. (2003); Fatma and Hala (2008); Kapentonov, et al. (2000) and Engestrom et al. (2001) Table (4) and Table (5).

The liver sections showed vacuolar degeneration of hepatocytes with nuclear pyknosis and mononuclear cells infiltration around the blood vessels as well as perivascular edema these results agreed with Sohair and Moursi (2003); Hala and Kawther (2006) and Fatma and Hala (2008).

The heart lesions revealed edema among the degenerated and necrosed cardiac muscle fibers. The kidney revealed mononuclear cells infiltrations and edema in between the renal lobules. These results agreed with Amal and Mohamed (2000), Dunber et al. (2000), Muhoirwa (2000), El. Demerdach et al. (2003) and Refat and Fatma (2006) where they recorded that, these lesions may be attributed to the infection with bacterial pathogens specially Pasteurella multocida as well as vascular damage due then circulating toxins of $E$. coli, and Pseudomonas aeuroginosa as well as the kidney revealed mono nuclear cells infiltration and edema between the renal lobules. These results mainly similar to those reported by El-Demerdech et al (2003). In the present study, the liver showed hemorrhages and haemosiderosis. They also showed diffused necrosis and severe congestion of the blood vessels the results agreed with Amal and Mohamed (2000), Kamel et al (2001), El- Demerdach et al. (2003); Hala and Kawther (2006) and Fatma and Hala (2008). There fore, a wide spread pathological changes in different organs were recorded. In few cases, the heart showed myocardial edema and necrosis of muscle layers of myocardium as well as serofibrinous to organized pericarditis. These results were nearly similar to that described by Fatma (1999); Kamel et al. (2001); El-Dermerdach et al. (2003); Sohair and Moursi (2003), Hala and Kowther (2006) and Fatma and Hala (2008).

The spleen showed necrosis in some areas, edema and lymphoid depletion, these results agreed with Mohamed (2000) and Mouchira et al (2001) who stated that lymphoid depletion and necrosis of white pulps in the spleen.

The lung showed hyperplasia and mucinous degeneration of the bronchial epithelium. The kidney showed lobular nephrosis and marked kidney coagulative necrosis. The results nearly similar to those reported by El- Demerdach et al (2003), Sohair and Moursi (2003) Hala and 
Kawther (2006) and Fatma and Hala(2008). So, Successful management and disinfection of farms must be carried with therapy to dominate the predisposing factor as much as possible.

Control of the ostrich farms should be supplied with different laboratories to do periodical examination of birds to sure that free from diseases. Inside each ostrich farm, the birds should be undergoing the supervision of veterinary medicine to reach for correct diagnosis to give suitable medication. At present no vaccination measures are recommended, but high standard biosecurity are required to prevent introduction of infections into flocks (Tally and Shan, 1996).

It could be concluded that the most bacterial pathogens which detected in ostrich farms were Pasteurella multocida, So. Successful management and disinfection of farms must be carried with therapy to eliminate the predisposing factor as much as possible.

The results of this study suggest that low hygienic measures at the farms slaughter houses and storage levels may be act as a factor in Pasteurella multocida contamination to minimizing risk of Pasteurella multocida. Hygienic measures should be improved in the farm, slaughter houses during transportation, storage and marketing, also sure that food handlers are not Pasteurella multocida carriers, in addition to rodents, wild birds and bests in and around farms.

\section{REFERENCES}

Amal, A.M.E. and Mohamed, M.H. (2000): "Bacterial septicaemia and enteritis in young ostrich in Egypt." Zag. Vet 28 (1) 293-320.

Bancroft, J.D; Stevens, A. and Turner, D.R. (1990): Theory and practice of Histological Technique. $3^{\text {rd }}$ Ed. Churchill. Living stone, Edinburgh, Famdom. Melbourne and New York.

Carter, G.R. and Rappay, D.E. (1962): Formalized erythrocytes in haemagglutination test for typing Pasteurella multocida.

Chang, C.F. (1982): Pasteurella multocida serotypes, biochemical characteristic and drug susceptibility - isolated in Taiwan. Taiwan J. of Vet. Med and animal Husbandry 40: 47-52.

Cooper, R.G. (2005): Bacterial, fungal and parasitic infection in ostrich Animal science Journal 76 (2), 97-106.

Deeming, D.C. and Ayers, L. (1994): Factors affecting the rate of growth of ostrich chicks in captivity. Vet. Rec. 135-617-622. 
Dunber, M.R.; wolcatt, R.B.; Rimiler, B.R. and Berlowskl, M.B. (2000): "Pasterellosis in free ranging neonatal pronghorn in orehon." wildlife Dis. 36 (2) 383-388.

El-Demerdach, M.Z.; Amal, A.M.E.; Hanan, M.F. A and sohair, Y.M. (2003): Bacterial infectious accompanying respiratory and gastrointestinal troubles in some ostrich farms in Egypt. Zag. Vet. J. (31) 2: 57-78.

El- Faki, M.G.; Abbas, O.M.; Haroun, E.M. and Abdel Magied E.M. (2002): Septicaemic pasteurellosis in ostriches in central Saudi Arabia Vet. J. 163 (2): 218-221.

Engstrom, B.; Garseth, A.H.; Christensen, J.P. and Halstad, G. (2001): Outbreak of avian Pasteurellosis and foul cholera in Norway in 1999 Norsk veterina ertides krift 113 (1) 15-19.

Fatma, M.Y. (1999): Clinicopathological studies on pasteurellosis in laboratory animals. M. V. Sc. Thesis, Department of clinical pathology. Fac. Vet. Med, Suez Canal University.

Fatma, M.Y. and Hala, M. El Genaidy (2008): Studies on bacterial septicemia and costode on ostrich at Ismailia province. Egypt. J. comp. path clinic. Path. Vol. 21 (1) 240-258.

Hala, M. El. Genaidy and Kawther, H. Sabah (2006): Bacteriological and Histopathological studies on Pasteurella infection in rabbits at Ismailia province. Kafr El Sheikh Vet. Med. J. Egypt 4 (2) 97-215.

Holt, J.G.; Krieg,N.R.; Sneath, P.A.H.; Staley, J.T. and Williams, S.T. (1996): Bergey's manual of determinative bacteriology, $9^{\text {th }}$ ed. ,Williams and Wilkins, Baltimore, Maryland, USA.

Huchzermeyer, F.W. (1996): Public heath risks of ostrich and codialemeat. Revue 16-559-604.

Huchzermeyer, F.W. (1997): Animal heath risks associated with ostrich products Revue. Scientifigue et technique 16-111-116.

Huchzermeyer, F.W. (1998): Disease of ostrich and other Ratites Agricultural research. Council, Pretoria south Africa.

Huchzermeyer, F.W. (1999): Vet. Problems in ostrich. Biology production and health $\mathrm{CAB}$ international proceeding 293-320.

Jaslow, B.W.; Ringler, D.H.; Rush, H.G. and Gloriso, J.C. (1981): Pasteurella associated Rhinitis of Rabbits efficacy of penicillin therapy. Laboratory Animal science 31 (4): 382-385.

Kamel, A.M.; Boushra, M.H. and Khafagy, A.A. (2001): "Studies on sudden death problem of ostrich chicks in Egypt." The Second 
International Scientific Conference Mansoura University Egypt 369-385.

Kapentanov, M.; Kapentanov, R.; Suvajdzic, L. and Velhner, M. (2000): Cholera caused by pasteruella in breeder flocks. Zivinarst (11): 211-312.

Mohamed L.E. (2000): "Pathological studies on biologic interaction Schistosomiasis and larva migrance in mice." $\mathrm{Ph}$. D., Parasitology Department, Fac. Vet. Med., Zag. Univ.

Mouchira, M.M.; Ibrahim, E.M; Sami, A.A. and Khaled, E. (2001): "Correlative pathological studies in pigeons nervous syndrome and some Helminth parasite." Egypt. J. Comp. and Clinic. Path., 14 (2): 43-57.

Moursi, K.M. and Husein, M.M. (2007): Studies an bacterial case of respiratory problems in ostrich and some appropriate treatment Suez canal Vet. Med, XII (1): 151-165.

Muhairwa, A.M. (2000): prevalence epidemiology and virulence of Pasterulla multocida and related organisms obtained from poultry and their animal contacts. Thesis $\mathrm{Ph}$. D Royal Vet. Agric. Univ. Copenhagen.

Nasef, S.A.; Badr, J.M. and Tanios, N.I. (2003): Isolation, identification and pathogenicity of some bacterial agents Isolated from ostriches. Assuit. Vet. Med. J. 49 (99) 194-206.

Okoh, A.E. (1980): An outbreak of pasteurellosis in Kano zoo. J. Wildlife Dis., 16: 3-5.

Quinn, P.J.; Carter, M.E.; Makery, B.K. and Carter, G.R. (1994): Pasteurella species. In: Clinical Veterinary Microbiology, Wolf publishing .Europe Limited, pp. 245-258.

Rabab, E.A. (2003): Studies of some bacterial pathogens causing Pneumoenteritis in ostrich chicks. M. V. Sc., Thesis Department of wild life management and zoo medicine. Fact. Vet. Med. Suez Canal University.

Refat, K. and Fatma, A.M. (2006): Studies on Pasteurella multocida and other bacterial pathogens associated with some problems in duck farms in Assuit Governorate. Assiut Vet. Med. J. 52 (108) 336-353.

Sahinduran, S. (2004): Isolation of E. coli and staphylococcus aureus from ostriches with conjunctivitis and respiratory disease Revue Med. Vet. 155 (3): 167-169. 
Snipes, K.P.; Hirsh, D.C.; Xastien, R.W.; Carpenter, T.E. and Mccapes, R.H. (1990): Homogeneity of characteristics of Pasteurella multocida isolates from turkeys and wildlife in California. Avian Dis., 34: 315-320.

Sohair, Y.M. and Moursi, K.M. (2003): Pastuerellosis in ostrich Egypt. J. Agric. Res 81 (2) 709-725.

Tally, and Shan, (1996): Husbandry, practices as related to infections and parasitic diseases of larmed Ratites. Rev. Sci, Tech off, Epiz 15 (1): 73-89.

Tully, T.N. (2000): Ratites in Avian Medicine $1^{\text {st }}$ Ed. Tully, T. N. Lawton M. P. C and Dorrestein G. M. Reed Educational and Professional publishing oxford England 228-233.

Tully, T.N. and Shan, M. (1998): "Ratites in Vet. Clinics of North America.", November 14 (3) W. B. sanders Company a division of Harcourt Brace, Company.

Zahraei, S. and Farashi, B.S. (2006): "Antibiotic. Susceptibility pattern of $E$. coli strains isolated from chickens with colisepticemia in Tabriz province.", Iran international. J. Pemlt. Sci 5 (7): 677684.

Table 1: Percentage of isolation of $P$. maltocida from ostriches cases in different Governorates: 